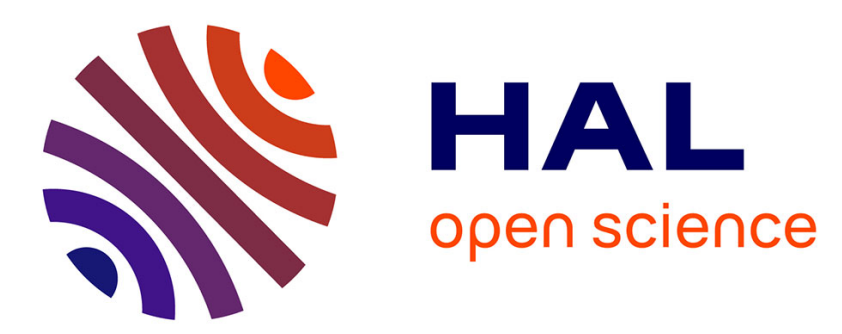

\title{
Genome-wide comparison of ultraviolet and ethyl methanesulphonate mutagenesis methods for the brown alga Ectocarpus
}

Olivier Godfroy, Akira F. Peters, Susana M. Coelho, J. Mark Cock

\section{- To cite this version:}

Olivier Godfroy, Akira F. Peters, Susana M. Coelho, J. Mark Cock. Genome-wide comparison of ultraviolet and ethyl methanesulphonate mutagenesis methods for the brown alga Ectocarpus. Marine Genomics, 2015, 24 (Part 1), pp.109-113. 10.1016/j.margen.2015.03.007 . hal-01142006

\section{HAL Id: hal-01142006 https: / hal.sorbonne-universite.fr/hal-01142006}

Submitted on 14 Apr 2015

HAL is a multi-disciplinary open access archive for the deposit and dissemination of scientific research documents, whether they are published or not. The documents may come from teaching and research institutions in France or abroad, or from public or private research centers.
L'archive ouverte pluridisciplinaire HAL, est destinée au dépôt et à la diffusion de documents scientifiques de niveau recherche, publiés ou non, émanant des établissements d'enseignement et de recherche français ou étrangers, des laboratoires publics ou privés. 


\title{
Genome-wide comparison of ultraviolet and ethyl
} methanesulphonate mutagenesis methods for the brown alga Ectocarpus

\author{
Olivier Godfroy ${ }^{1}$, Akira F. Peters ${ }^{2}$, Susana M. Coelho ${ }^{1}$, J. Mark Cock ${ }^{1, *}$
}

15orbonne Université, UPMC Univ Paris 06, CNRS, Algal Genetics Group, UMR 8227, Integrative Biology of Marine Models, Station Biologique de Roscoff, CS 90074, F-29688, Roscoff, France

${ }^{2}$ Bezhin Rosko, 29250 Santec, France

* Author for correspondence

\begin{abstract}
Ectocarpus has emerged as a model organism for the brown algae and a broad range of genetic and genomic resources are being generated for this species. The aim of the work presented here was to evaluate two mutagenesis protocols based on ultraviolet irradiation and ethyl methanesulphonate treatment using genome resequencing to measure the number, type and distribution of mutations generated by the two methods. Ultraviolet irradiation generated a greater number of genetic lesions than ethyl methanesulphonate treatment, with more than 400 mutations being detected in the genome of the mutagenised individual. This study therefore confirms that the ultraviolet mutagenesis protocol is suitable for approaches that require a high density of mutations, such as saturation mutagenesis or Targeting Induced Local Lesions in Genomes (TILLING).
\end{abstract}

Keywords: brown algae, Ectocarpus, ethyl methanesulphonate, mutagenesis, ultraviolet Abbreviations: EMS, ethyl methanesulphonate; UV, ultraviolet, SNP, single nucleotide polymorphism, CDS, coding sequence 


\section{Introduction}

The filamentous brown alga Ectocarpus has been the object of phycological research since the nineteenth century and has played a central role in several important discoveries, including for example the characterisation of brown algal pheromones, the discovery of brown algal viruses and the characterisation of its UV sexual system [1-6]. These advances, together with several features of this organism such as its small size and its capacity to complete its life cycle under laboratory conditions, led to Ectocarpus being proposed as a model organism for the brown algae in 2004 [7]. Since this initial proposal, a number of genomic resources have been developed for this organism, the most notable being the publication of a complete genome sequence in 2010 [8]. In addition, considerable effort has been put into creating genetic resources for Ectocarpus and the resources currently available include mutagenesis and classical genetic protocols, a genetic map and inbred lines [2, 9-11]. These genetic tools are currently being used to address a number of questions about brown algal biology, including for example life cycle regulation, sex determination and regulation of morphogenesis $[2,9$, $12,13]$. Several of these studies involve the analysis of genetic mutants.

Ultraviolet (UV-C) irradiation of gametes is currently the most widely used method for generating genetic mutants in Ectocarpus. However, the current protocol has been optimised based on dose lethality and very little is known about the genomic effects of irradiation in terms of the number and types of mutations that are induced. Moreover, UV-C irradiation has not been compared with alternative, chemical mutagenesis approaches that have proved to be highly efficient in other model systems. For example, chemical mutagenesis with the alkylating agent ethyl methanesulphonate (EMS) has been shown to efficiently induce mutations in the flowering plant model Arabidopsis $[14,15]$.

The objective of the work reported here was to compare optimised UV-C and EMS mutagenesis protocols for Ectocarpus by directly analysing the genetic lesions caused by the two mutagens using genome-wide, sequence-based analysis of mutant individuals. The results of these analyses indicated that UV-C mutagenesis generates a higher density of genetic lesions per individual than EMS mutagenesis. Moreover, based on the number of mutations generated (more than 400 per individual) UV-C mutagenesis should be suitable for approaches that require collections of individuals each carrying a 
large number of mutations such as saturation mutagenesis or Targeting Induced Local Lesions in Genomes (TILLING) [16]. We also describe the construction of a strain adapted for these and other mutagenesis-based approaches.

\section{Results and discussion}

\subsection{Construction of an optimised strain for mutagenesis and mutant analysis}

Conditions have been defined for the completion of the Ectocarpus life cycle under laboratory conditions $[17,18]$ but difficulties can be encountered during culture depending on the strain being grown. This is particularly the case when working with mutant lines, which may exhibit marked morphological or physiological modifications. Problems are most often encountered at the stage when the sporophyte produces the unilocular sporangia in which meiosis occurs. To circumvent this problem, we constructed a mutant strain carrying recessive mutations that maintain it in the gametophyte generation. For this, both the ouroboros (oro [9]) and immediate upright (imm [12]) mutations were introduced into the same strain and, in the process, two backcrosses were carried out to reduce the number of additional mutations carried by the strain (see Fig. 1 and the Methods section for details). The oro and imm mutations cause this strain (designated Ec197-21) to continually reiterate the gametophyte generation so that any mutants generated can be directly crossed for genetic analysis (genetic mapping, complementation tests, etc.). This is an advantage over wild type strains, which are maintained as the sporophyte generation, making it necessary to induce the production of unilocular sporangia and transition to the gametophyte generation before the strains can be crossed (Fig. 2). As the oro and imm mutations are

recessive, any diploid progeny produced by crossing can express the sporophyte program and therefore progress through the life cycle, allowing further genetic manipulations such as the generation of segregating populations for gene mapping (Fig. 2).

\subsection{Optimisation of the EMS mutagenesis protocol}


Strain Ec197-21 was mutagenised using UV-C irradiation and treatment with the chemical mutagen EMS in order to compare the efficacy of the two mutagenesis methods. UV-C mutagenesis was carried out using the protocol described by Coelho et al. [9] except that it was necessary to adjust the period of irradiation to $30 \mathrm{~min}$ to obtain a lethality of $50 \%$.

To optimise the EMS mutagenesis protocol, Ec197-21 gametes were treated with different concentrations of EMS for either five or 16 hours at $13^{\circ} \mathrm{C}$ (Table 1). Based on gamete lethality, treatment with $0.25 \% \mathrm{v} / \mathrm{v}$ EMS for 16 hours was selected as the optimal treatment.

\subsection{Sequence analysis of UV-C and EMS mutagenised individuals}

To assess and compare the effects of UV-C and EMS mutagenesis at the genome level, large-scale mutagenesis experiments were carried out using either irradiation with UV-C light for 30 minutes or treatment with $0.25 \%$ v/v EMS for 16 hours. One individual was then selected at random from each of the two mutagenic treatments (named 20-1 and 18-1 for the UV-C and EMS treatments, respectively) and multiplied clonally for DNA extraction. Genome resequencing was carried out by generating $12,455,830,634$ bp (58x coverage) and 10,668,189,461 bp (50x coverage) of Illumina HiSeq2500 125 bp pairedend sequence data for the UV-C and EMS mutated individuals, respectively. Cleaned and trimmed sequence data for the two samples were optimally mapped to the Ectocarpus sp. strain Ec32 reference genome using Bowtie2 and the GATK suite and sequence variants were called using three different algorithms: the Samtools programs mpileup and bcftools view [19], SHORE qVar [20] and GATK UnifiedGenotyper [21]. We only retained variants identified by at least two of these algorithms. Moreover, to limit the detection of false positive mutations, only variants with sequence coverage of between 20x and 50x were retained and filters were also applied for Phred-scaled variant quality score (50) and variant frequency (0.95). Polymorphisms present in the parent strains were identified and eliminated by mapping Illumina sequence data for the female parent Ec597 [2] onto the male parent (Ec32) reference genome [8]. Finally, all variants that were found in both the UV-C and the EMS mutagenised individuals were eliminated as we considered it extremely unlikely that identical mutations would be produced in the 
two strains and these more likely corresponded to errors in the Ec32 reference sequence.

Resequencing detected a total of 442 and 129 mutations in the UV-C and EMS mutagenised individuals, respectively (Table 2). UV-C irradiation and EMS treatment therefore induced one mutation every $375 \mathrm{kbp}$ (a frequency of 2.67e $\mathrm{e}^{-6}$ ) and 1,296 kbp (a frequency of $7.72 \mathrm{e}^{-7}$ ), respectively (Table 3). These counts probably underestimate the number of mutations in the genomes of the two individuals to some extent because only just over $84 \%$ of the genome was sequenced at a coverage of 20-50x in both cases and mutations in the remaining $16 \%$ of the genome would not have been detected or would have been discarded. Based on this analysis, however, the UV-C mutagenesis protocol clearly produced a higher number of mutations per individual than EMS mutagenesis.

Twenty-six of the UV-induced mutations were selected at random and further analysed by PCR amplification and Sanger sequencing of the mutated region. All but four of the 26 mutations were confirmed by this approach. Of the four mutations that were not confirmed, two corresponded either to sequencing errors in the reference sequence or to polymorphisms that were already present in the Ec197-21 strain before mutagenesis and two to loci where variation from the reference sequence was not confirmed by Sanger sequencing. The Sanger sequencing analysis therefore confirmed $84.6 \%$ of the mutations detect by the Illumina resequencing pipeline. Extrapolating this confirmation rate to the entire set of mutations detected by the latter approach, we predict that approximately 374 of the 442 mutations would be validated by Sanger sequencing (corresponding to a mutation rate of $2.26 \mathrm{e}^{-6}$ per base). However, note again that the Illumina approach was limited to $84 \%$ of the genome (regions with $20 \mathrm{x}$ to $50 \mathrm{x}$ coverage) and therefore would not have detected all the mutations induced by the UV-C treatment. Overall, therefore, the Sanger sequencing analysis indicated that the large majority of the variants detected by the Illumina resequencing pipeline were bona fide mutations.

EMS has been used extensively to generate large mutant collections for flowering plant species and, consequently, a considerable amount of information is available about the density of mutations induced by treatment with this mutagen. Frequencies of EMSinduced mutations of between $1 \mathrm{e}^{-4}$ to $1 \mathrm{e}^{-6}$ have been observed in these studies, corresponding to one mutation every $400 \mathrm{kbp}$ in Arabidopsis [22], every $200 \mathrm{kbp}$ in Pisum sativum [23] and every $146 \mathrm{kbp}$ to $848 \mathrm{kbp}$ in Melon [24]. The mutation frequency 
observed in the present study was lower than that reported in these previous studies. This difference may have been due to a number of factors. First, it is possible that, despite the precautions taken to minimise instability of the EMS during the mutagenic treatment (seawater buffered at $\mathrm{pH} 7$, treatment at a low temperature of $13^{\circ} \mathrm{C}$ and incubation in the dark), the molecule may have lost some of its potency over time in the seawater medium. Second, in the absence of an easily scored recurring phenotype, lethality was used to optimise the mutagenic dose $50 \%$ lethality, i.e. similar to the lethality rates observed with flowering plants; Table 1), and it is possible that this indirect method of measuring the effect of the mutagen did not result in an optimal treatment regime.

EMS has been shown to predominantly induce point mutations (mainly guanine to adenine) through alkylation of guanine residues $[15,25,26]$. Only $14 \%$ of the mutations detected in strain 18-1 were of this type, suggesting that part of the EMS mutagenic action may have been through indirect, non-canonical effects due, for example, to toxicity.

UV radiation is known to exert at least part of its mutagenic effect via the formation of covalent bonds between adjacent pyrimidine nucleotides (formation of dipyrimidines), which result principally in cytosine to thymine transitions ( $\mathrm{C}>\mathrm{T}$ or CC>TT [27]). However, UV irradiation can induce other types of point mutation and the formation of dipyrimidines can lead to double-strand DNA breaks during DNA replication, resulting in deletions [28]. A significant proportion (62.4\%) of the mutations detected in the genome of strain 20-1 corresponded to UV signature mutations; we detected one UV-signature mutation per $600 \mathrm{kbp}$ (or a mutation frequency of $1.6 \mathrm{e}^{-6}$ per base).

Detailed analysis of the 442 UV-induced mutations showed that 58 (13.1\%) were located in the coding regions of genes and that $36(8.1 \%)$ of these mutations modified the coding region of the gene by causing either missense or nonsense mutations.

\subsection{Conclusions}

This study demonstrated, based on genome resequencing, that UV-C mutagenesis of Ectocarpus gametes results in a large number of genetic lesions, 442 in the randomly selected individual analysed here. The majority of these mutations are SNPs and the 
types of mutation observed are consistent with what is known about the mode of action of this mutagen. UV-C mutagenesis was found to generate genetic lesions more effectively than chemical mutagenesis with EMS. The number of mutations observed per individual is sufficient to envisage genome-wide mutagenesis approaches such as saturation mutagenesis and TILLING. For example, based on the 58 mutations detected in coding regions in the 20-1 strain, a population of $2000 \mathrm{UV}$-mutagenised individuals could be expected to contain approximately 116,000 CDS mutations or more than seven mutant alleles for each gene in the Ectocarpus genome.

\section{Methods}

\subsection{Ectocarpus strains and culture}

Both UV-C and EMS mutagenesis was carried out on a strain (Ec197-21) that carried both the oro [9] and the imm [12] mutations but which had been backcrossed twice to reduce the number of mutations elsewhere in the genome (Fig. 1). For this, the original oro mutant strain (Ec494), which is a UV-mutagenised, clonal descendant of the genome-sequenced strain Ec32 [8], was crossed with a female line carrying the imm mutation (Ec419). Ec419 had been derived by crossing the original, spontaneous imm mutant line, Ec137, with a sister, Ec25. Both Ec137 and Ec25 are siblings of the genomesequenced strain Ec32. The diploid sporophyte (Ec566) derived from the cross between Ec494 and Ec419 gave rise to a female oro imm gametophyte (Ec597) that was backcrossed with Ec32 to further remove UV-induced mutations other than oro. This cross produced a diploid sporophyte, Ec197, which gave rise to the female oro imm backcrossed strain, Ec197-21, that was used for the mutagenesis experiments. Strains were cultivated under standard conditions [18]. Strain Ec197-21 is available on request.

\subsection{UV and EMS mutagenesis of Ectocarpus gametes}

UV mutagenesis was carried out as described by Coelho et al. [9] except that the gametes were irradiated for $30 \mathrm{~min}$ rather than $45 \mathrm{~min}$. Briefly, gametes were irradiated with a UV (254 nm) lamp for $30 \mathrm{~min}$ immediately after release from plurilocular gametangia. Irradiated gametes were allowed to settle in the dark at $13^{\circ} \mathrm{C}$ for $4 \mathrm{~h}$. Petri dishes were then transferred to a culture chamber at $13{ }^{\circ} \mathrm{C}$ and cultivated as described above. For the 
EMS mutagenesis, gametes were released synchronously, as described, into natural, unsupplemented seawater and about $100 \mu \mathrm{l}$ of gametes were immediately diluted in 2 $\mathrm{ml}$ of Tris-buffered (100mM Tris- $\mathrm{HCl} \mathrm{pH}$ 7) natural seawater containing different concentrations of EMS. After incubation for either five or 16 hours at $13^{\circ} \mathrm{C}$ in the dark, the gametes were washed three times with $80 \mathrm{ml}$ of Tris-buffered natural seawater for about 30 min with gentle shaking.

\subsection{Genome resequencing and identification of mutations}

Genome resequencing was carried out by generating 125 bp paired-end reads using Illumina HiSeq2500 technology (Fasteris, Switzerland). Raw sequence data were cleaned and trimmed using Prinseq [29]. Reads were trimmed from both ends to remove nucleotides with quality less than 20 and reads were then only retained if they were longer than 50 nucleotides, had a mean quality of at least 25 and no nondetermined nucleotides. Reads were mapped to the Ec32 reference genome using Bowtie2 [30] and the Indels Realigner and Base Score Recalibration programs of the GATK suite [21, 31] were used to improve read alignment and quality parameters, respectively. Sequencing depth per base was estimated using the Samtools depth program and the estimation used to determine a relevant sequencing coverage working interval. Variants were then identified by independently running three different variantcalling programs: Samtools mpileup and bcftools, SHORE qVar and the GATK UnifiedGenotyper. Variants were called for each of the mutagenised strains the EMS mutagenised strain 18-1 and the UV mutagenised strain 20-1) and for the female parental strain Ec597. A number of filters were applied in order to retain only high quality variants. These involved selecting only variant loci where 1) coverage was to a depth of between 20 and 50,2 ) the variant sequence was at a frequency of 0.95 or higher and 3) the Phred-scaled variant quality score was over 50. These filters were either applied during variant calling (SHORE qVar) or afterwards (Samtools mpileup and Unified Genotyper) using bcftools. The VFCtools suite was then used (vcf-isec command) to compare vcf files and remove variants shared by two or more strains in order to retain only variants that were unique to each mutant strain. A list of putative mutations was established for each of the two mutants by comparing the results from the three variant calling programs and retaining only variants that had been identified 
by at least two programs. Twenty-six variants were then randomly selected from this

list of putative mutations and further analysed by PCR amplification of the local genomic region $\left(1.5 \mathrm{mM} \mathrm{MgCl}_{2}, 0.25 \mathrm{mM}\right.$ each $\mathrm{dNTP}, 0.5 \mathrm{mM}$ each oligonucleotide primer [Eurogentec], 5\% DMSO, $0.05 \mathrm{U} / \mu \mathrm{l}$ GoTaq $^{\circledR}$ DNApolymerase [Promega, USA]) and Sanger sequencing of the amplified product (MWG Eurofins, Germany). PCR primers were designed using Primer3 (http://bioinfo.ut.ee/primer3-0.4.0/) and Sanger sequences were analysed using the CodonCodeAligner software (http://www.codoncode.com/aligner/).

\section{Acknowledgements}

This work was supported by the Centre National de la Recherche Scientifique and the University Pierre and Marie Curie. O.G. was supported by the Agence Nationale de la Recherche Investment for the Future project Idealg, the European Union Infrastructure project Assemble and the CNRS.

\section{References}

[1] D.G. Müller, Sex expression in aneuploid gametophytes of the brown alga Ectocarpus siliculosus (Dillw.) Lyngb., Arch. Protistenk. Bd, 117 (1975) 297-302.

[2] S. Ahmed, J.M. Cock, E. Pessia, R. Luthringer, A. Cormier, M. Robuchon, L. Sterck, A.F. Peters, S.M. Dittami, E. Corre, M. Valero, J.M. Aury, D. Roze, Y. Van de Peer, J. Bothwell, G.A. Marais, S.M. Coelho, A Haploid System of Sex Determination in the Brown Alga Ectocarpus sp, Curr Biol, 24 (2014) 1945-1957.

[3] S.M. Coelho, D. Scornet, S. Rousvoal, N. Peters, L. Dartevelle, A.F. Peters, J.M. Cock, Ectocarpus: A model organism for the brown algae, Cold Spring Harbor Protoc, 2012 (2012) 193-198.

[4] D.G. Müller, L. Jaenicke, M. Donike, T. Akintobi, Sex Attractant in a Brown Alga: Chemical Structure, Science 171 (1971) 815-817.

[5] B. Charrier, S. Coelho, A. Le Bail, T. Tonon, G. Michel, P. Potin, B. Kloareg, C. Boyen, A. Peters, J. Cock, Development and physiology of the brown alga Ectocarpus siliculosus: two centuries of research., New Phytol, 177 (2008) 319-332.

[6] D.G. Müller, H. Kawai, B. Stache, S.T.J. Lanka, A virus infection in the marine brown alga Ectocarpus siliculosus (Phaeophyceae), Botanica Acta, 103 (1990) 72-82. [7] A.F. Peters, D. Marie, D. Scornet, B. Kloareg, J.M. Cock, Proposal of Ectocarpus siliculosus (Ectocarpales, Phaeophyceae) as a model organism for brown algal genetics and genomics, J Phycol, 40 (2004) 1079-1088.

[8] J.M. Cock, L. Sterck, P. Rouzé, D. Scornet, A.E. Allen, G. Amoutzias, V. Anthouard, F. Artiguenave, J. Aury, J. Badger, B. Beszteri, K. Billiau, E. Bonnet, J. Bothwell, C. Bowler, C. Boyen, C. Brownlee, C. Carrano, B. Charrier, G. Cho, S. Coelho, J. Collén, E. Corre, C. Da Silva, L. Delage, N. Delaroque, S. Dittami, S. Doulbeau, M. Elias, G. Farnham, C. Gachon, B. Gschloessl, S. Heesch, K. Jabbari, C. Jubin, H. Kawai, K. Kimura, B. Kloareg, F. Küpper, D. 
Lang, A. Le Bail, C. Leblanc, P. Lerouge, M. Lohr, P. Lopez, C. Martens, F. Maumus, G. Michel, D. Miranda-Saavedra, J. Morales, H. Moreau, T. Motomura, C. Nagasato, C. Napoli, D. Nelson, P. Nyvall-Collén, A. Peters, C. Pommier, P. Potin, J. Poulain, H. Quesneville, B. Read, S. Rensing, A. Ritter, S. Rousvoal, M. Samanta, G. Samson, D. Schroeder, B. Ségurens, M. Strittmatter, T. Tonon, J. Tregear, K. Valentin, P. von Dassow, T. Yamagishi, Y. Van de Peer, P. Wincker, The Ectocarpus genome and the independent evolution of multicellularity in brown algae., Nature, 465 (2010) 617-621.

[9] S.M. Coelho, O. Godfroy, A. Arun, G. Le Corguillé, A.F. Peters, J.M. Cock, OUROBOROS is a master regulator of the gametophyte to sporophyte life cycle transition in the brown alga Ectocarpus., Proc Natl Acad Sci U S A, 108 (2011) 11518-11523.

[10] S.M. Coelho, D. Scornet, S. Rousvoal, N. Peters, L. Dartevelle, A.F. Peters, J.M. Cock, Genetic crosses between Ectocarpus strains, Cold Spring Harb Protoc, 2012 (2012) 262265.

[11] S. Heesch, G.Y. Cho, A.F. Peters, G. Le Corguillé, C. Falentin, G. Boutet, S. Coëdel, C. Jubin, G. Samson, E. Corre, S.M. Coelho, J.M. Cock, A sequence-tagged genetic map for the brown alga Ectocarpus siliculosus provides large-scale assembly of the genome sequence., New Phytol, 188 (2010) 42-51.

[12] A.F. Peters, D. Scornet, M. Ratin, B. Charrier, A. Monnier, Y. Merrien, E. Corre, S.M. Coelho, J.M. Cock, Life-cycle-generation-specific developmental processes are modified in the immediate upright mutant of the brown alga Ectocarpus siliculosus., Development, 135 (2008) 1503-1512.

[13] A. Le Bail, B. Billoud, S. Le Panse, S. Chenivesse, B. Charrier, ETOILE Regulates Developmental Patterning in the Filamentous Brown Alga Ectocarpus siliculosus, Plant Cell, 23 (2011) 1666-1678.

[14] M. Koornneef, L.W. Dellaert, J.H. van der Veen, EMS- and radiation-induced mutation frequencies at individual loci in Arabidopsis thaliana (L.) Heynh, Mutat Res, 93 (1982) 109-123.

[15] E.A. Greene, C.A. Codomo, N.E. Taylor, J.G. Henikoff, B.J. Till, S.H. Reynolds, L.C. Enns, C. Burtner, J.E. Johnson, A.R. Odden, L. Comai, S. Henikoff, Spectrum of chemically induced mutations from a large-scale reverse-genetic screen in Arabidopsis, Genetics, 164 (2003) 731-740.

[16] M. Kurowska, A. Daszkowska-Golec, D. Gruszka, M. Marzec, M. Szurman, I. Szarejko, M. Maluszynski, TILLING: a shortcut in functional genomics., J Appl Genet, 52 (2011) 371-390.

[17] D.G. Müller, Life-cycle of Ectocarpus siliculosus from Naples, Italy, Nature, 26 (1964) 1402.

[18] S.M. Coelho, D. Scornet, S. Rousvoal, N.T. Peters, L. Dartevelle, A.F. Peters, J.M. Cock, How to cultivate Ectocarpus, Cold Spring Harb Protoc, 2012 (2012) 258-261.

[19] H. Li, B. Handsaker, A. Wysoker, T. Fennell, J. Ruan, N. Homer, G. Marth, G. Abecasis, R. Durbin, The Sequence Alignment/Map format and SAMtools, Bioinformatics, 25 (2009) 2078-2079.

[20] S. Ossowski, K. Schneeberger, R.M. Clark, C. Lanz, N. Warthmann, D. Weigel, Sequencing of natural strains of Arabidopsis thaliana with short reads, Genome Res, 18 (2008) 2024-2033.

[21] A. McKenna, M. Hanna, E. Banks, A. Sivachenko, K. Cibulskis, A. Kernytsky, K. Garimella, D. Altshuler, S. Gabriel, M. Daly, M.A. DePristo, The Genome Analysis Toolkit: a MapReduce framework for analyzing next-generation DNA sequencing data, Genome Res, 20 (2010) 1297-1303. 
[22] C.M. McCallum, L. Comai, E.A. Greene, S. Henikoff, Targeted screening for induced mutations, Nat Biotechnol, 18 (2000) 455-457.

[23] M. Dalmais, J. Schmidt, C. Le Signor, F. Moussy, J. Burstin, V. Savois, G. Aubert, V. Brunaud, Y. de Oliveira, C. Guichard, R. Thompson, A. Bendahmane, UTILLdb, a Pisum sativum in silico forward and reverse genetics tool, Genome Biol, 9 (2008) R43.

[24] F. Dahmani-Mardas, C. Troadec, A. Boualem, S. Leveque, A.A. Alsadon, A.A. Aldoss, C. Dogimont, A. Bendahmane, Engineering melon plants with improved fruit shelf life using the TILLING approach, PLoS One, 5 (2010) e15776.

[25] S. Flibotte, M.L. Edgley, I. Chaudhry, J. Taylor, S.E. Neil, A. Rogula, R. Zapf, M. Hirst, Y. Butterfield, S.J. Jones, M.A. Marra, R.J. Barstead, D.G. Moerman, Whole-genome profiling of mutagenesis in Caenorhabditis elegans, Genetics, 185 (2010) 431-441.

[26] E. Bautz, E. Freese, On the mutagenic effects of alkylating agents, Proc Natl Acad Sci U S A, 46 (1960) 1585-1594.

[27] H. Ikehata, T. Ono, The mechanisms of UV mutagenesis, J Radiat Res, 52 (2011) 115125.

[28] G. Hendriks, F. Calleja, A. Besaratinia, H. Vrieling, G.P. Pfeifer, L.H. Mullenders, J.G. Jansen, N. de Wind, Transcription-dependent cytosine deamination is a novel mechanism in ultraviolet light-induced mutagenesis, Curr Biol, 20 (2010) 170-175. [29] R. Schmieder, R. Edwards, Quality control and preprocessing of metagenomic datasets, Bioinformatics, 27 (2011) 863-864.

[30] B. Langmead, C. Trapnell, M. Pop, S.L. Salzberg, Ultrafast and memory-efficient alignment of short DNA sequences to the human genome, Genome Biol, 10 (2009) R25. [31] M.A. DePristo, E. Banks, R. Poplin, K.V. Garimella, J.R. Maguire, C. Hartl, A.A. Philippakis, G. del Angel, M.A. Rivas, M. Hanna, A. McKenna, T.J. Fennell, A.M. Kernytsky, A.Y. Sivachenko, K. Cibulskis, S.B. Gabriel, D. Altshuler, M.J. Daly, A framework for variation discovery and genotyping using next-generation DNA sequencing data, Nat Genet, 43 (2011) 491-498. 
Tables

Table 1

Optimisation of the EMS mutagenesis protocol.

\begin{tabular}{|c|c|c|}
\hline $\begin{array}{c}\text { EMS concentration (\% } \\
\mathbf{v} / \mathbf{v})\end{array}$ & $\begin{array}{c}\text { Duration of } \\
\text { treatment (h) }\end{array}$ & $\begin{array}{c}\text { Estimated lethality (\% } \\
\text { kill) }\end{array}$ \\
\hline 0 & 5 & 0 \\
\hline 0.5 & 5 & 25 \\
\hline 1.0 & 5 & 70 \\
\hline 0 & 16 & 0 \\
\hline 0.25 & 16 & 43 \\
\hline 0.5 & 16 & 21 \\
\hline
\end{tabular}

\section{Table 2}

Detection of UV-C- and EMS-induced mutations by genome resequencing. Underlined numbers indicate mutagen signature mutations. SNP, single nucleotide polymorphism; CDS, coding sequence.

\begin{tabular}{|c|c|c|c|c|c|}
\hline \multicolumn{2}{|c|}{ Mutagen } & \multicolumn{2}{|c|}{ EMS } & \multicolumn{2}{|c|}{ UV-C } \\
\hline $\begin{array}{r}\text { T } \\
\text { ider } \\
\text { mut }\end{array}$ & $\begin{array}{l}\text { Ied } \\
\text { ons }\end{array}$ & \multicolumn{2}{|c|}{129} & \multicolumn{2}{|c|}{442} \\
\hline \multirow{2}{*}{\multicolumn{2}{|c|}{$\begin{array}{c}\text { Insertions } \\
\text { (average size nt) } \\
\text { Deletions } \\
\text { (average size nt) }\end{array}$}} & $\begin{array}{c}5 \\
(2.2) \\
\end{array}$ & $3.88 \%$ & $\frac{8}{(2.6)}$ & $1.81 \%$ \\
\hline & & $\begin{array}{c}8 \\
(3.5) \\
\end{array}$ & $6.20 \%$ & $\frac{7}{(11)}$ & $\underline{1.58} \%$ \\
\hline \multicolumn{2}{|c|}{ SNPS } & \multicolumn{2}{|c|}{$116 \quad 89.92 \%$} & 427 & $96.61 \%$ \\
\hline \multirow{4}{*}{ 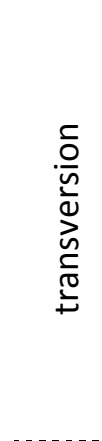 } & $\begin{array}{l}C>T \\
G>A\end{array}$ & \multicolumn{2}{|c|}{$8 \underline{18} \quad \underline{13.95 \%}$} & 276 & $62.44 \%$ \\
\hline & $\begin{array}{l}A>G \\
T>C\end{array}$ & \multicolumn{2}{|c|}{$5 \quad 30 \quad 23.26 \%$} & 64 & $14.48 \%$ \\
\hline & $\begin{array}{l}A>C \\
T>G\end{array}$ & 9 & $6.98 \%$ & 28 & $6.33 \%$ \\
\hline & $\begin{array}{l}C>A \\
G>T\end{array}$ & \multicolumn{2}{|c|}{$22 \quad 17.05 \%$} & 26 & $5.88 \%$ \\
\hline \multirow{2}{*}{ 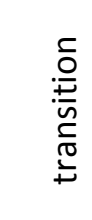 } & $\begin{array}{l}A>T \\
T>A\end{array}$ & $\begin{array}{l}6 \\
4\end{array}$ & $7.75 \%$ & 19 & $4.30 \%$ \\
\hline & $\begin{array}{l}C>G \\
G>C\end{array}$ & 27 & $20.93 \%$ & $\begin{array}{ll}7 & 14 \\
7 & \end{array}$ & $3.17 \%$ \\
\hline \multicolumn{2}{|c|}{$\begin{array}{c}\text { CDS } \\
\text { mutations }\end{array}$} & 7 & $5.43 \%$ & 58 & $13.12 \%$ \\
\hline & & 2 & $1.55 \%$ & 22 & $4.98 \%$ \\
\hline $\mathrm{mi}$ & ense & 5 & $3.88 \%$ & 35 & $7.92 \%$ \\
\hline no & ense & 0 & $0.00 \%$ & 1 & $0.23 \%$ \\
\hline
\end{tabular}


Table 3

Number and density of mutations by class

\begin{tabular}{|c|c|c|c|c|}
\hline Mutant strain & Mutation class & $\begin{array}{l}\text { Number of } \\
\text { mutations }\end{array}$ & $\begin{array}{l}\text { Average interval } \\
\text { between mutations } \\
(\mathrm{kbp})\end{array}$ & $\begin{array}{c}\text { Mutation } \\
\text { frequency (per } \\
\text { base) }\end{array}$ \\
\hline \multirow{5}{*}{$\begin{array}{l}18.1 \text { mutant } \\
\text { (EMS) }\end{array}$} & Total & 129 & 1296 & $7.72 \mathrm{e}^{-7}$ \\
\hline & SNPs & 116 & 1441 & $6.94 \mathrm{e}^{-7}$ \\
\hline & $\begin{array}{c}\text { Mutagen signature } \\
\text { mutations }\end{array}$ & 18 & 9287 & $1.08 \mathrm{e}^{-7}$ \\
\hline & Insertions & 5 & 33434 & $2.99 \mathrm{e}^{-8}$ \\
\hline & Deletions & 8 & 20896 & $4.79 \mathrm{e}^{-8}$ \\
\hline \multirow{5}{*}{$\begin{array}{l}20.1 \text { mutant } \\
(U V-C)\end{array}$} & Total & 442 & 375 & $2.67 e^{-6}$ \\
\hline & SNPs & 427 & 388 & $2.58 \mathrm{e}^{-6}$ \\
\hline & $\begin{array}{l}\text { Mutagen signature } \\
\text { mutations }\end{array}$ & 276 & 600 & $1.66 \mathrm{e}^{-6}$ \\
\hline & Insertions & 7 & 23685 & $4.22 \mathrm{e}^{-8}$ \\
\hline & Deletions & 8 & 20724 & $4.83 e^{-8}$ \\
\hline
\end{tabular}




\section{Figures}

Fig. 1. Construction of strain Ec197-21, which is optimised for the TILLING protocol. See section 3.2 for details. UV-C, ultraviolet mutagenesis; 1n, haploid, 2n, diploid.

Fig. 2. Life cycles of wild type and oro imm double mutant Ectocarpus strains. The wild type Ectocarpus life cycle (in black) involves alternation between a diploid sporophyte generation and a haploid, dioicous gametophyte generation. Haploid meio-spores are produced via meiosis (R!) in unilocular sporangia on the sporophyte and these spore develop into gametophytes following release. Gametophytes produce either male or female gametes, which fuse with a gamete of the opposite sex to produce a zygote (F!), the diploid initial cell of the next sporophyte generation. The oro imm double mutant cannot initiate the sporophyte program and its gametes therefore reiteratively develop parthenogenetically as gametophytes (in grey). However, as the oro and imm mutations are recessive, zygotes formed by fusion with wild type gametes are able to initiate the sporophyte program and enter the normal life cycle (dark grey arrows). n, haploid, $2 n$, diploid. 


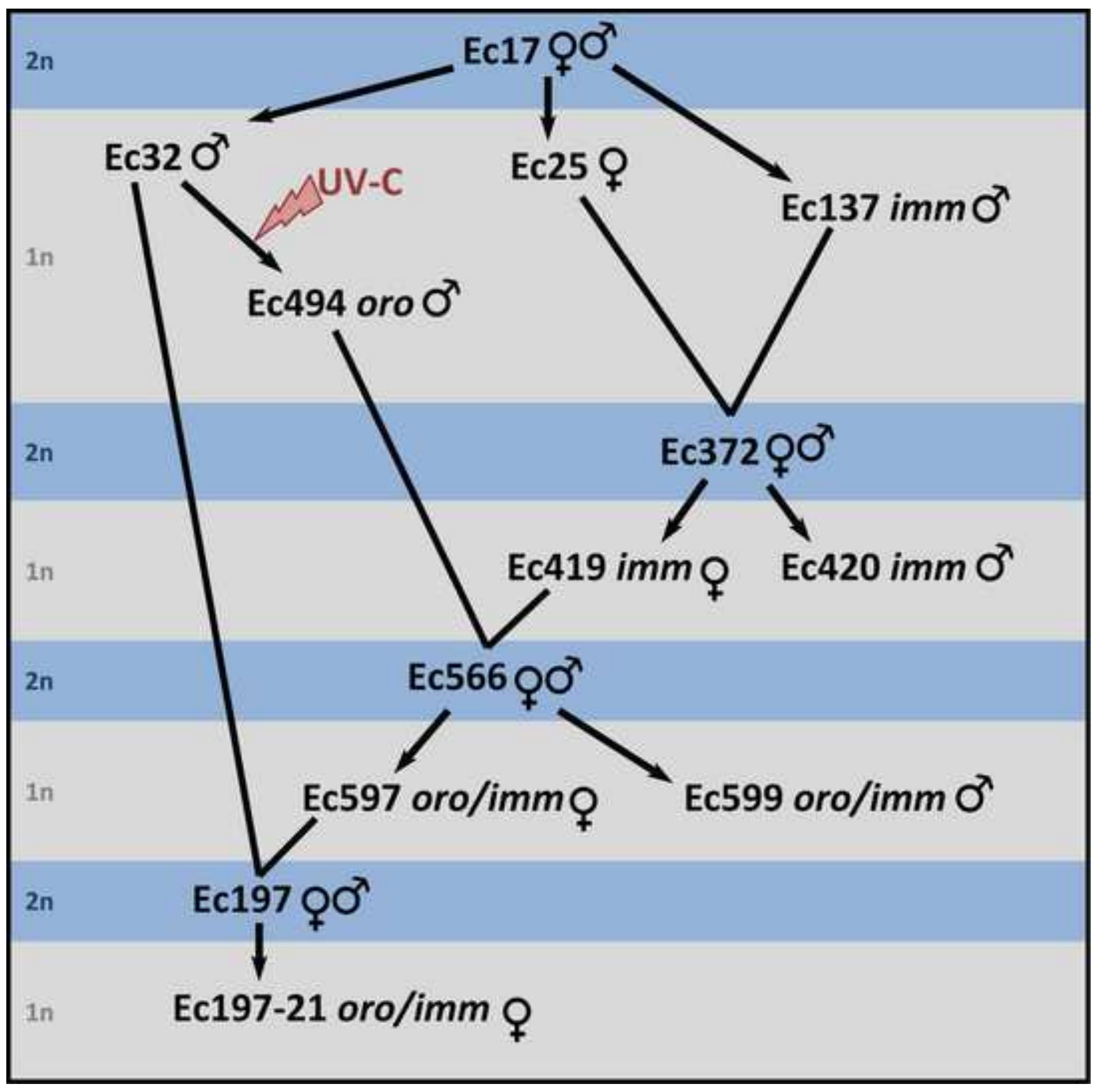




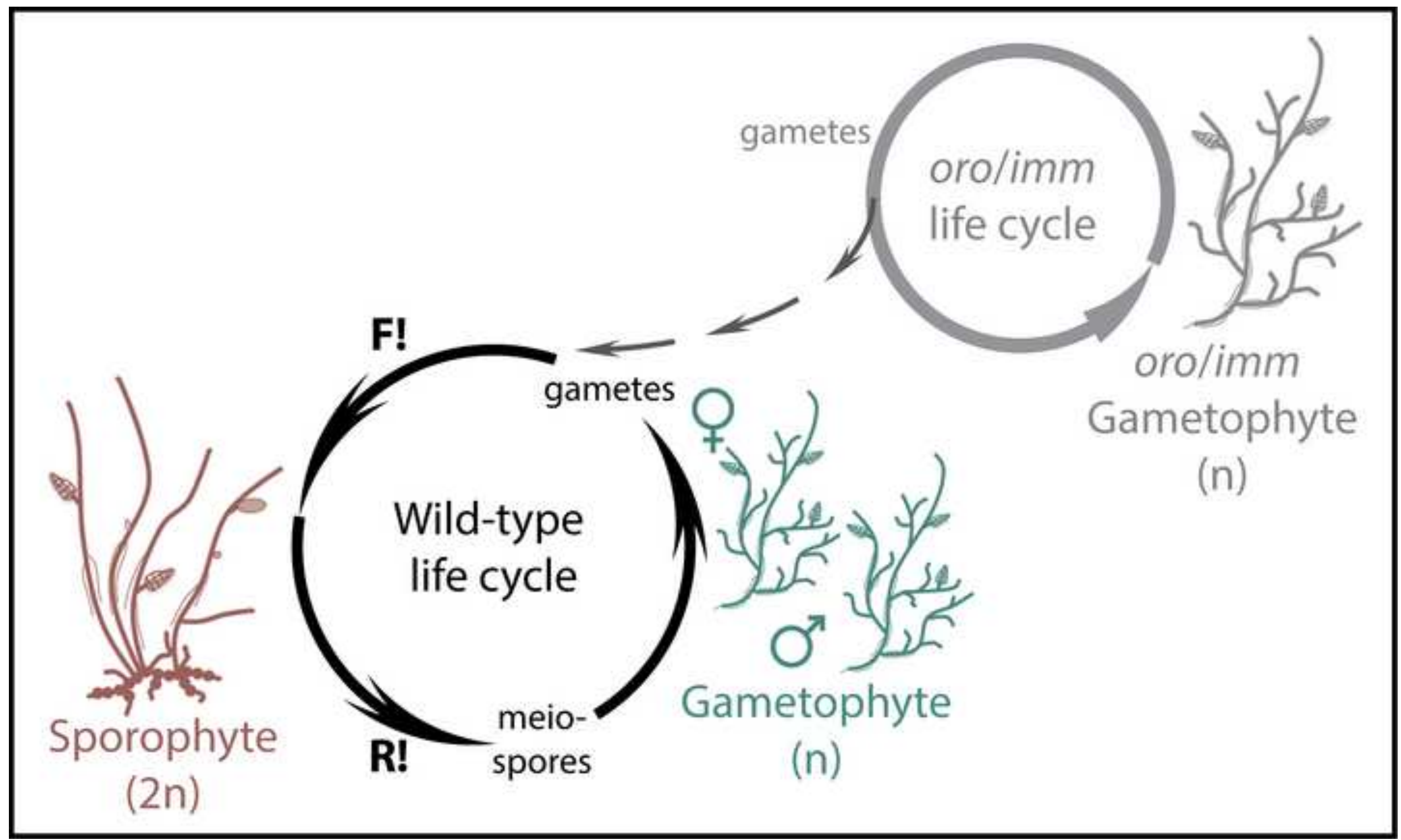

